\title{
To Assess the Clinical Value of the RPAD Index in Dogs with Varying Degrees of Pulmonary Hypertension
}

\author{
Dushyant Nijhawan', Rakesh K Chawla², Manju Saxena', Shikha Dixit', Vidushi Sharma ${ }^{1}$ \\ 'Department of Anaesthesiology, KDMC Hospital and Research Centre, Mathura, U.P., ${ }^{2}$ Department of Dermatology, KDMC Hospital and Research Centre, \\ Mathura, U.P.
}

\section{Abstract}

Background: The gold standard for pulmonary artery pressure measurement is right heart catheterization. The present study was conducted to assess the clinical value of the RPAD index in dogs with varying degrees of pulmonary hypertension. Subjects and Methods: The present study was conducted on 40 dogs. Dogs were divided in four groups according to the TRPG value $(<36 \mathrm{mmHg}, 36-50 \mathrm{mmHg}, 51-75 \mathrm{mmHg}$, or $>75 \mathrm{mmHg}$ ). In all dogs, presence of signs commonly associated with PH was recorded. Results: Out of 40 dogs, male dogs were 25 and female dogs were 15. Common clinical features were coughing in 24 , tachypnea in 11 , weakness in 18 , dyspnea in 27 , syncope in 5 and hemoptysis in 34 . The mean heart rate in group I was 130.2, in group II was 121.4, in group III was 141.3 and in group IV was 147.5. Clinical score in group I was 2.5, in group II was 3.7, in group III was 5.11 and in group IV was 5.8. Mean radiology score was 1.3 in group I, 2.4 in group II, 2.9 in group III and 3.8 in group IV. Fractional shortening was $46.5 \%$ in group I, 50.3\% in group II, 55.4\% in group III and 53.2\% in group IV. The difference was significant $(\mathrm{P}<0.05)$. Conclusion: Authors found significant difference in mean heart rate, clinical score, radiology score and fractional shortening in dogs with different pulmonary pressure.

Keywords: Catheterization, Dog, Pulmonary pressure.

Corresponding Author: Dr. Vidushi Sharma, Department of Anaesthesiology, KDMC Hospital and Research Centre, Mathura, U.P.

Received: December 2019

Accepted: December 2019

\section{Introduction}

Pulmonary hypertension $(\mathrm{PH})$ is defined as increased pulmonary blood pressure. The gold standard for pulmonary artery pressure measurement is right heart catheterization. ${ }^{[1]}$ However, this technique is invasive and requires general anesthesia, which is unacceptable for most owners and compromised patients. Therefore, the diagnosis of $\mathrm{PH}$ in a veterinary clinic relies mainly on Doppler echocardiographic estimated pulmonary arterial systolic and diastolic pressure derived from the tricuspid regurgitation (TR) pressure gradient (TRPG) and pulmonary regurgitation $(\mathrm{PR})$ pressure gradient, respectively. ${ }^{[2]} \mathrm{A}$ TRPG $\geq 36 \mathrm{mmHg}$ is indicative of $\mathrm{PH}$. In dogs with myxomatous mitral valve degeneration (MMVD), a TRPG $\geq 50 \mathrm{mmHg}$ predicts a poor outcome. When TR and PR are absent or unavailable, diagnosis of $\mathrm{PH}$ relies on echocardiographic findings, thoracic radiography, and clinical signs. ${ }^{[3]}$

The diagnosis of $\mathrm{PH}$ is often based on indirect and subjective parameters, specifically when tricuspid regurgitation and/or pulmonary insufficiency are not present, which only help to partially quantify the disease severity. ${ }^{[4]}$ Recently, the Right Pulmonary Artery Distensibility Index (RPAD Index), which is calculated as the difference in diameter of the right pulmonary artery in systole and diastole as measured by M-mode, was validated as a valuable method for estimating the presence and severity of $\mathrm{PH}$ in heartworm-infected dogs. ${ }^{[5]}$ The present study was conducted to assess the clinical value of the RPAD index in dogs with varying degrees of pulmonary hypertension.

\section{Subjects and Methods}

The present study was conducted on 40 dogs. The experiments were approved by the Ethical Committee. Dogs were divided in four groups according to the TRPG value (<36 mmHg, 36-50 mmHg, 51-75 mmHg, or >75 mmHg). In all dogs, presence of signs commonly associated with $\mathrm{PH}$ (syncope, dyspnea, ascites, signs of right heart failure), three points each; presence of clinical signs not strictly associated with PH (lethargy, weakness, weight loss, coughing), 2 points; and abnormalities on clinical examination (e.g., murmur) or other clinical signs unrelated to PH (e.g., polyuria), one point was recorded. Results thus obtained were subjected to statistical analysis. P value less than 0.05 was considered significant.

\section{Results}

[Table 1] shows that out of 40 dogs, male dogs were 25 and female dogs were 15. 
Table 1: Distribution of dogs

\begin{tabular}{|l|l|l|}
\hline Total- 40 & Male dogs & Female dogs \\
\hline Gender & 25 & 15 \\
\hline Number & 25 & \\
\hline
\end{tabular}

Table 2: Clinical features in dogs

\begin{tabular}{|l|l|l|}
\hline Clinical features & Number & \multirow{2}{*}{ P value } \\
\hline Coughing & 24 & \multirow{2}{*}{} \\
\hline Tachypnea & 11 & \\
\hline Weakness & 18 & \\
\hline Dyspnea & 27 & \\
\cline { 1 - 2 } Syncope & 5 & \\
\hline Hemoptysis & 34 & \\
\hline
\end{tabular}

[Table 2, Figure 1] shows that common clinical features were coughing in 24 , tachypnea in 11 , weakness in 18 , dyspnea in 27, syncope in 5 and hemoptysis in 34 . The difference was significant $(\mathrm{P}<0.05)$.

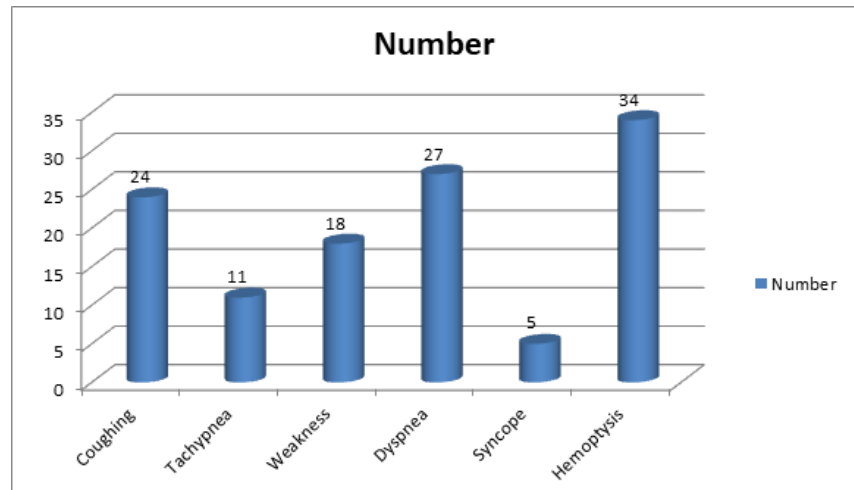

Figure 1: Clinical features in dogs

Table 3: Comparison of parameters
\begin{tabular}{|l|l|l|l|l|l|}
\hline Parameters & Group & $\begin{array}{l}\text { Group } \\
\text { I }\end{array}$ & $\begin{array}{l}\text { Group } \\
\text { III }\end{array}$ & $\begin{array}{l}\text { Group } \\
\text { IV }\end{array}$ & $\begin{array}{l}\text { P } \\
\text { value }\end{array}$ \\
\hline Heart rate & 130.2 & 121.4 & 141.3 & 147.5 & 0.01 \\
\hline Clinical score & 2.5 & 3.7 & 5.1 & 5.8 & 0.04 \\
\hline $\begin{array}{l}\text { Radiology } \\
\text { score }\end{array}$ & 1.3 & 2.4 & 2.9 & 3.8 & 0.01 \\
\hline $\begin{array}{l}\text { fractional } \\
\text { shortening \% }\end{array}$ & 46.5 & 50.3 & 55.4 & 53.2 & 0.12 \\
\hline
\end{tabular}

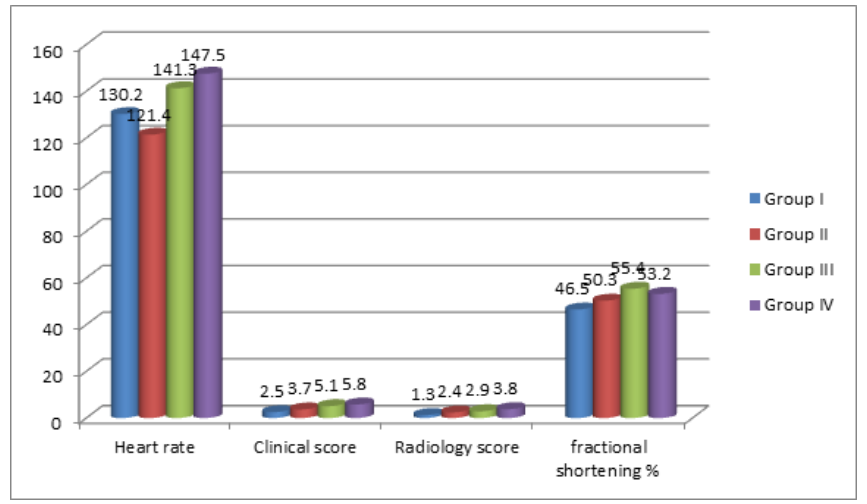

Figure 2: Comparison of parameters

[Table 3, Figure 2] shows that mean heart rate in group I was 130.2 , in group II was 121.4 , in group III was 141.3 and in group IV was 147.5. Clinical score in group I was
2.5, in group II was 3.7, in group III was 5.11 and in group IV was 5.8. Mean radiology score was 1.3 in group I, 2.4 in group II, 2.9 in group III and 3.8 in group IV. Fractional shortening was $46.5 \%$ in group I, $50.3 \%$ in group II, $55.4 \%$ in group III and $53.2 \%$ in group IV. The difference was significant $(\mathrm{P}<0.05)$.

\section{Discussion}

The characteristics of the PA are related to PH severity, and serve as noninvasive indices of $\mathrm{PH}$ in humans because they are quantifiable by echocardiography, computed tomography angiography, and magnetic resonance imaging. These indices are reliable early indicators of $\mathrm{PH}$ and predict mortality and response to medication in humans. ${ }^{[6]}$

The right pulmonary artery distensibility (RPAD) index correlates strongly with non-invasive and invasive PA pressure measurements in dogs with PH secondary to heartworm infection; its predictive ability has also been demonstrated in $\mathrm{PH}$ caused by other diseases, such as MMVD and right-to-left or left-to-right patent ductus arteriosus. ${ }^{[7]}$ The advantage of the RPAD index is that it is easily acquired, not technically difficult to derive, and measurable in the absence of TR or PR. However, there is no radiographic evidence of its correlation with clinical signs. ${ }^{[8]}$ The present study was conducted to assess the clinical value of the RPAD index in dogs with varying degrees of pulmonary hypertension.

In present study, out of 40 dogs, male dogs were 25 and female dogs were 15 . Kasai et al, ${ }^{[9]}$ found that the right pulmonary artery distensibility (RPAD) index has been used in dogs with pulmonary hypertension (PH) caused by heartworm infection, myxomatous mitral valve disease, or patent ductus arteriosus. The RPAD index and the ratios of acceleration time to peak pulmonary artery flow (AT) and to the ejection time of pulmonary artery flow (ET) were recorded for each dog. The owners were contacted for follow-up assessments. The findings indicated that the RPAD index was correlated with the TRPG $(\mathrm{R} 2=0.362$, $\mathrm{p}$ $<0.001)$. The survival time was significantly shorter in dogs with an RPAD index $\leq 21 \%$ that were followed up for 3 months and in dogs with an RPAD index $\leq 24 \%$ that were followed up for 1 year. Thus, the RPAD index was correlated with the TRPG and could predict the clinical outcome in dogs with PH caused by various diseases.

We found that common clinical features were coughing in 24 , tachypnea in 11 , weakness in 18 , dyspnea in 27 , syncope in 5 and hemoptysis in 34. The mean heart rate in group I was 130.2 , in group II was 121.4, in group III was 141.3 and in group IV was 147.5 . Clinical score in group I was 2.5 , in group II was 3.7 , in group III was 5.11 and in group IV was 5.8. Mean radiology was 1.3 in group I, 2.4 in group II, 2.9 in group III and 3.8 in group IV. Fractional shortening was $46.5 \%$ in group I, $50.3 \%$ in group II, $55.4 \%$ in group III and $53.2 \%$ in group IV.

Abel et al10 compared some echocardiographic parameters commonly used to estimate $\mathrm{PH}$ in 93 dogs infected by D. immitis and evaluated the impact of the parasite burden, 
microfilaremia, sex or origin of the dog (clientowned/shelter). None of the studied echocardiographic variables seemed useful in the estimation of the evaluated clinical aspects, except for the PA/Ao ratio for parasite burden. The RPAD Index was determined in 88 of the dogs; of these, $70.4 \%$ had $\mathrm{PH}$ (mild: $37.5 \%$, moderate: $19.3 \%$, severe: $13.6 \%$ ). This Index showed non-significant differences according to microfilaremia, sex, origin or parasite burden. Symptomatic dogs showed PH more often and displayed more severe $\mathrm{PH}$, in addition the presence of symptoms was greater among dogs with high burden; on the other hand $64.4 \%$ of asymptomatic dogs had some degree of $\mathrm{PH}$ according to the RPAD Index. Apart from the PA/Ao ratio, the other evaluated echocardiographic variables were not useful in evaluating of the hypertensive status of the heartworm-infected dog compared to the RPAD Index.

\section{Conclusion}

Authors found significant difference in mean heart rate, clinical score, radiology score and fractional shortening in dogs with different pulmonary pressure.

\section{References}

1. Pyle RL, Abbott J, MacLean H. Pulmonary hypertension and cardiovascular sequelae in 54 dogs. Int $\mathrm{J}$ Appl Res Vet Med 2004;2:99-109.

2. Paradies P, Spagnolo PP, Amato ME, Pulpito D, Sasanelli M. Doppler echocardiographic evidence of pulmonary hypertension in dogs: a retrospective clinical investigation. Vet Res Commun 2014;38:63-71.

3. Kellihan HB, Stepien RL. Pulmonary hypertension in dogs: diagnosis and therapy. Vet Clin North Am Small Anim Pract 2010;40:623-641.

4. Chiavegato D, Borgarelli M, D'Agnolo G, Santilli RA. Pulmonary hypertension in dogs with mitral regurgitation attributable to myxomatous valve disease. Vet Radiol Ultrasound 2009;50:253-258.

5. Venco L, Mihaylova L, Boon JA. Right Pulmonary Artery Distensibility Index (RPAD Index). A field study of an echocardiographic method to detect early development of pulmonary hypertension and its severity even in the absence of regurgitant jets for Doppler evaluation in heartworm-infected dogs. Vet Parasitol 2014;206:60-66.

6. Nakamura K, Morita T, Osuga T, Morishita K, Sasaki N, Ohta H, Takiguchi M. Prognostic value of right ventricular Tei index in dogs with myxomatous mitral valvular heart disease. J Vet Intern Med 2016;30:69-75.

7. Visser LC, Im MK, Johnson LR, Stern JA. Diagnostic value of right pulmonary artery distensibility index in dogs with pulmonary hypertension: comparison with Doppler echocardiographic estimates of pulmonary arterial pressure. J Vet Intern Med 2016;30:543-552.

8. Kang KW, Chang HJ, Kim YJ, Choi BW, Lee HS, Yang WI, Shim $\mathrm{CY}$, Ha J, Chung N. Cardiac magnetic resonance imaging-derived pulmonary artery distensibility index correlates with pulmonary artery stiffness and predicts functional capacity in patients with pulmonary arterial hypertension. Circ J 2011;75:2244-2251.

9. Kasai H, Sugiura T, Tanabe N, Sakurai Y, Yahaba M, Matsuura Y, Shigeta A, Kawata N, Sakao S, Kasahara Y, Tatsumi K. Electrocardiogram-gated 320-slice multidetector computed tomography for the measurement of pulmonary arterial distensibility in chronic thromboembolic pulmonary hypertension. PLoS One 2014;9:e111563.

10. Abel E, Jankowski A, Pison C, Luc Bosson J, Bouvaist H, Ferretti GR. Pulmonary artery and right ventricle assessment in pulmonary hypertension: correlation between functional parameters of ECG-gated CT and right-side heart catheterization. Acta Radiol 2012;53:720-727.

Copyright: () the author(s), 2019. It is an open-access article distributed under the terms of the Creative Commons Attribution License (CC BY 4.0), which permits authors to retain ownership of the copyright for their content, and allow anyone to download, reuse, reprint, modify, distribute and/or copy the content as long as the original authors and source are cited.

How to cite this article: Nijhawan D, Chawla RK, Saxena M, Dixit S, Sharma V. To Assess the Clinical Value of the RPAD Index in Dogs with Varying Degrees of Pulmonary Hypertension. Asian J. Med. Res. 2019;8(4):AN17-AN19.

DOI: dx.doi.org/10.21276/ajmr.2019.8.4.AN5

Source of Support: Nil, Conflict of Interest: None declared. 